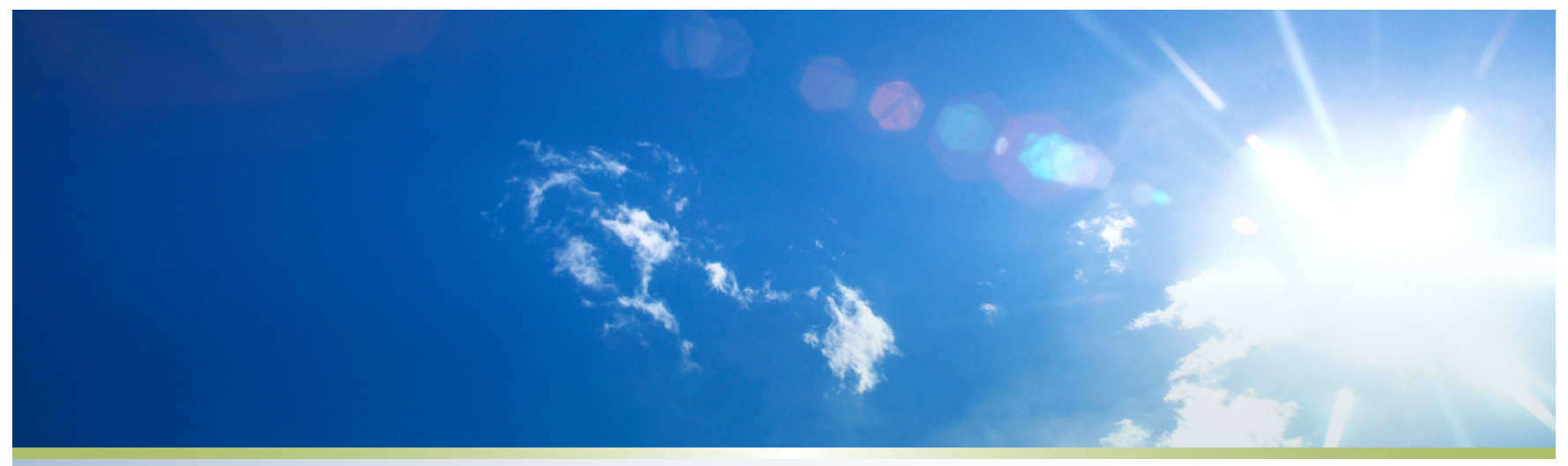

\title{
1: Scenarios
}

\section{Future Climate in the Pacific Northwest}

Philip W. Mote ${ }^{1,2}$ and Eric P. Salathé Jr. ${ }^{1}$

\section{Abstract}

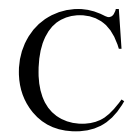

limate models used in the Intergovernmental Panel on Climate Change (IPCC) Fourth Assessment Report (AR4) on the whole reproduce the observed seasonal cycle and 20th century warming trend of $0.8^{\circ} \mathrm{C}\left(1.5^{\circ} \mathrm{F}\right)$ in the Pacific Northwest, and point to much greater warming for the next century. These models project increases in annual temperature of, on average, $1.1^{\circ} \mathrm{C}\left(2.0^{\circ} \mathrm{F}\right)$ by the $2020 \mathrm{~s}, 1.8^{\circ} \mathrm{C}\left(3.2^{\circ} \mathrm{F}\right)$ by the $2040 \mathrm{~s}$, and $3.0^{\circ} \mathrm{C}$ $\left(5.3^{\circ} \mathrm{F}\right)$ by the $2080 \mathrm{~s}$, compared with the average from 1970 to 1999 , averaged across all climate models. Rates of warming range from 0.1 to $0.6^{\circ} \mathrm{C}\left(0.2^{\circ}\right.$ to $\left.1.0^{\circ} \mathrm{F}\right)$ per decade. Projected changes in annual precipitation, averaged over all models, are small $(+1$ to $+2 \%)$, but some models project an enhanced seasonal cycle with changes toward wetter autumns and winters and drier summers.

Changes in nearshore sea surface temperatures, though smaller than on land, are likely to substantially exceed interannual variability, but coastal upwelling changes little. Rates of $21^{\text {st }}$ century sea level rise will depend on poorly known factors like ice sheet instability in Greenland and Antarctica, and could be as low as 20th century values $(20 \mathrm{~cm}, 8$ ") or as large as $1.3 \mathrm{~m}(50 ")$.

1JISAO Climate Impacts Group, University of Washington, Seattle, Washington 98195-5672

${ }^{2}$ Oregon Climate Change Research Institute, College of Oceanic and Atmospheric Sciences, Oregon State Univ., Corvallis, Oregon $97331-5503$ 


\section{Global Climate Models}

Envisioning global climate in a future with much higher greenhouse gases requires the use of physically based numerical models of the ocean, atmosphere, land, and ice, often called global climate models (GCMs) or climate system models. A common set of simulations using 21 GCMs was coordinated through the Intergovernmental Panel on Climate Change (IPCC), described in the IPCC 2007 report (Randall et al. 2007), and archived by the Program for Climate Model Diagnostics and Intercomparisons (PCMDI). These models typically resolve the atmosphere with between 6,000 and 15,000 grid squares horizontally, and with between 12 and 56 atmospheric layers. All GCMs in the PCMDI archive include a fully resolved global ocean model, usually with higher resolution than the atmospheric model, and nearly all include models of sea ice dynamics and models of the land surface. By calculating energy fluxes between the sun, atmosphere, and surface, these models compute surface temperature distributions that compare well with observations. Details of the models, as well as references, can be found in Table 8.1 of Randall et al. 2007.

Simulations of $21^{\text {st }}$ century climate require projections of future greenhouse gases and sulfate aerosols (which reflect sunlight and also promote cloud formation, thereby offsetting greenhouse gases locally), more than 40 of which were produced under the auspices of the IPCC (SRES, Nakicenovic et al.2000) after considering a wide range of future socioeconomic changes. Three of these "SRES" scenarios were commonly chosen for forcing the GCMs: B1, A1B, and A2. The climate forcing of all scenarios, including B2 and the older IS92a used in the Second Assessment report (Figure 1) is similar until about 2020 owing primarily to the long lifetime of coal fired electric power plants and of the major greenhouse gases. A2 produces the highest climate forcing by the end of the century, but before mid-century, none of the scenarios is consistently the highest. Because more modeling groups ran A1B than A2, and since our focus for this study was on midcentury change, we chose $\mathrm{A} 1 \mathrm{~B}$ as the higher emissions scenario and $\mathrm{B} 1$ as the low emissions scenario for our analysis of $21^{\text {st }}$ century PNW climate. We have analyzed available A2 runs as well, as shown in Figures 8, 11, and 12, but we emphasize A1B and B1. Though B1 is the lowest of the IPCC illustrative scenarios, it still produces changes in climate that many scientists call "dangerous" (Schellnhuber et al. 2006) - a threshold that a growing number of political leaders have stated their intention to avoid. At the high end, scenario A1FI (not shown) results in even higher climate forcing by 2100 than A2 or A1B. Mid-2000s global emissions of $\mathrm{CO}_{2}$ exceeded even the A1FI scenario (Raupach et al. 2007). Whether these exceedingly high emissions will continue into the future is beyond our expertise to judge.

On the PCMDI web site (esg.llnl.gov), all modeling centers provided simulations of 20th century climate using observed solar, volcanic, and greenhouse gas forcing. Twenty modeling centers provided simulations of $21^{\text {st }}$ century climate with the A1B scenario, 19 with B1, and 17 with A2, for a total of 56 runs. These form the basis for the analysis presented in most of the other chapters in this assessment report. In some cases several different model runs were provided for each scenario; we chose Run 1 
IPCC scenarios, radiative forcing

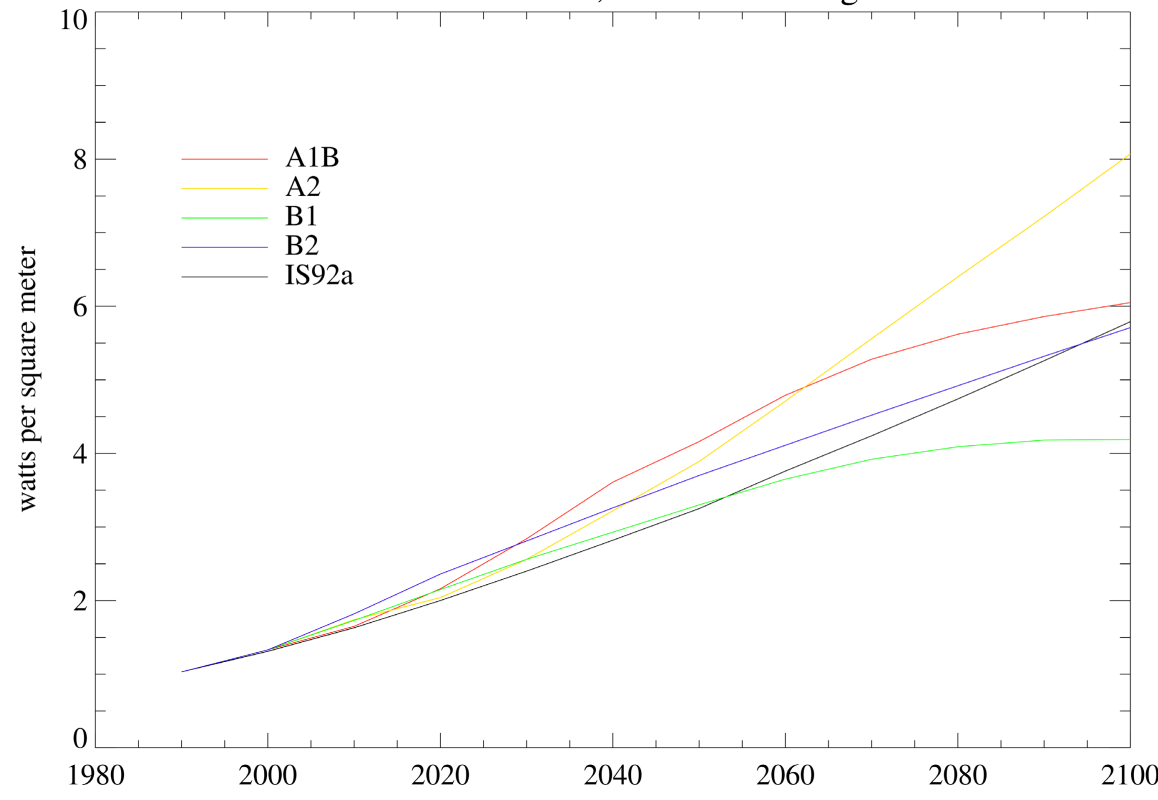

except as noted in Appendix A. This set of models is larger than the set available in 2005 when similar analysis was performed for the Northwest (Mote et al. 2005, 10 models) and California (Cayan et al. 2007, 12 models but emphasizing two).

Randall et al. (2007) and CCSP (2008) evaluated the models' fidelity in simulating various aspects of global climate, and also calculated each model's climate sensitivity. The modeled climate sensitivity is a measure of the model's response to doubled $\mathrm{CO}_{2}$, and has historically been calculated in two ways: either the "equilibrium climate sensitivity" or the "transient climate response" (TCR, ibid.). The equilibrium climate sensitivity is defined as the globally averaged temperature change in a simulation with a doubling of $\mathrm{CO}_{2}$, in which the simulation is long enough for the global temperature to reach equilibrium. Because the climate system takes a long time to come into equilibrium, the calculation of the equilibrium climate sensitivity was typically performed only in models with a very simple ocean component, which was standard before the mid-1990s. By the late 1990s, most models included a sophisticated ocean, and running such a model to equilibrium would require a great deal of computer resources. The TCR was a more practical metric of models' sensitivity. The TCR is defined as the global mean temperature change at the time of $\mathrm{CO}_{2}$ doubling in a simulation in which the $\mathrm{CO}_{2}$ increased at 1\%/year (roughly IS92a, the black curve in Figure 1). The range of values of TCR reported by Randall et al. (2007) was $1.2-2.6^{\circ} \mathrm{C}$ (their Table 8.2).

\section{Model Evaluation: 20th Century Climate of the Northwest}

The domain used in the rest of the chapters in this study is the state of Washington. However, because the state is represented by only a few grid points in a typical GCM, for examining the GCMs we use the larger domain of the Pacific Northwest, defined as the region between $124^{\circ}$ and $111^{\circ}$
Figure 1. Globally averaged radiative forcing by greenhouse gases and sulfate aerosols, for four of the six illustrative scenarios plus the older IS92a scenario, from IPCC (2001) Appendix II.3. In this study we use A1B and B1. Differences between scenarios grow after about 2020. 
west longitude, $41.5^{\circ}$ to $49.5^{\circ}$ north latitude: Washington, Oregon, Idaho, western Montana, and a small slice of adjacent states and British Columbia. Models have different spatial resolutions, but the number of model grid points enclosed in this latitude-longitude box is between 6 and 91 .

In any prediction exercise the first question should be, how well can the predictive model simulate the past? In this section we examine the 20 models' simulation of $20^{\text {th }}$ century climate in the Pacific Northwest, a step not discussed by Cayan et al. (2007) in their two-model study of climate change in California. We use a regionally averaged time series formed by averaging the temperature and precipitation values at all the Northwest grid points. The reason for such averaging is that variations in model climate on scales smaller than a few grid cells is not meaningful. Put another way, the models represent the variations of climate that would occur on a smooth planet with similar land-sea distributions and large smooth bumps where Earth has major mountain ranges.

Besides model resolution, another consideration in comparing global models with observations is that there are different ways to calculate "observed" regionally averaged temperature and precipitation. A common approach is to average weather station data into latitude-longitude boxes or into geographically defined "climate divisions" and combine these areas into a state or regional average with area weighting; this was how Mote et al. (2005) compared climate models with observations. The drawback of this approach is that it does not account for the contribution to a regional average of high terrain, which has very few weather stations. A better estimate interpolates (horizontally) and extrapolates (vertically) observations to a uniform, high-resolution grid (e.g., Hamlet and Lettenmaier 2005). Such an estimate, however, would be unsuitable for comparing with climate model output, which lacks the vertical relief.

A third approach is to assimilate observed data into a weather prediction model at the spatial resolution of climate models, as has been done for the NCEP/NCAR reanalysis (Kalnay et al. 1996). This approach processes observations in a manner most similar to a global climate model, or in other words constrains a model twice a day to be consistent with observations, and hence it is perhaps the fairest comparison with climate models and is the one we used previously (Mote and Salathé 2009). However, in this analysis we use $0.5^{\circ}-0.5^{\circ}$ (latitude-longitude) gridded data of the University of East Anglia Climatic Research Unit (CRU) version 2.02 (Mitchell et al. 2004). We area-average the data over the same domain as the climate models and use monthly means for 1901-2000.

We begin with a comparison of the annual mean difference, or bias, between models and CRU for 1970-99. Most models have a slight cold bias, and both the mean and median bias is $1.8^{\circ} \mathrm{C}\left(3.3^{\circ} \mathrm{F}\right)$ (Figure 2). The models with least bias in annual average temperature are GISS-ER, MIROC-hi, INMCM3, and CNRM. For precipitation (Figure 3), all models have a wet bias, and for some the bias exceeds $50 \%$. The mean bias is $6.0 \mathrm{~cm} /$ month (41\%). Models with lowest bias are BCCR, GISS_er, HadCM, PCM1, and CGCM_T47. Note that no model falls in the best five for both temperature and precipitation, and likewise no model falls in the worst five for both temperature and precipitation. Comparing these results with those obtained using NCEP, the NCEP regional average temperature was 
Temperature bias
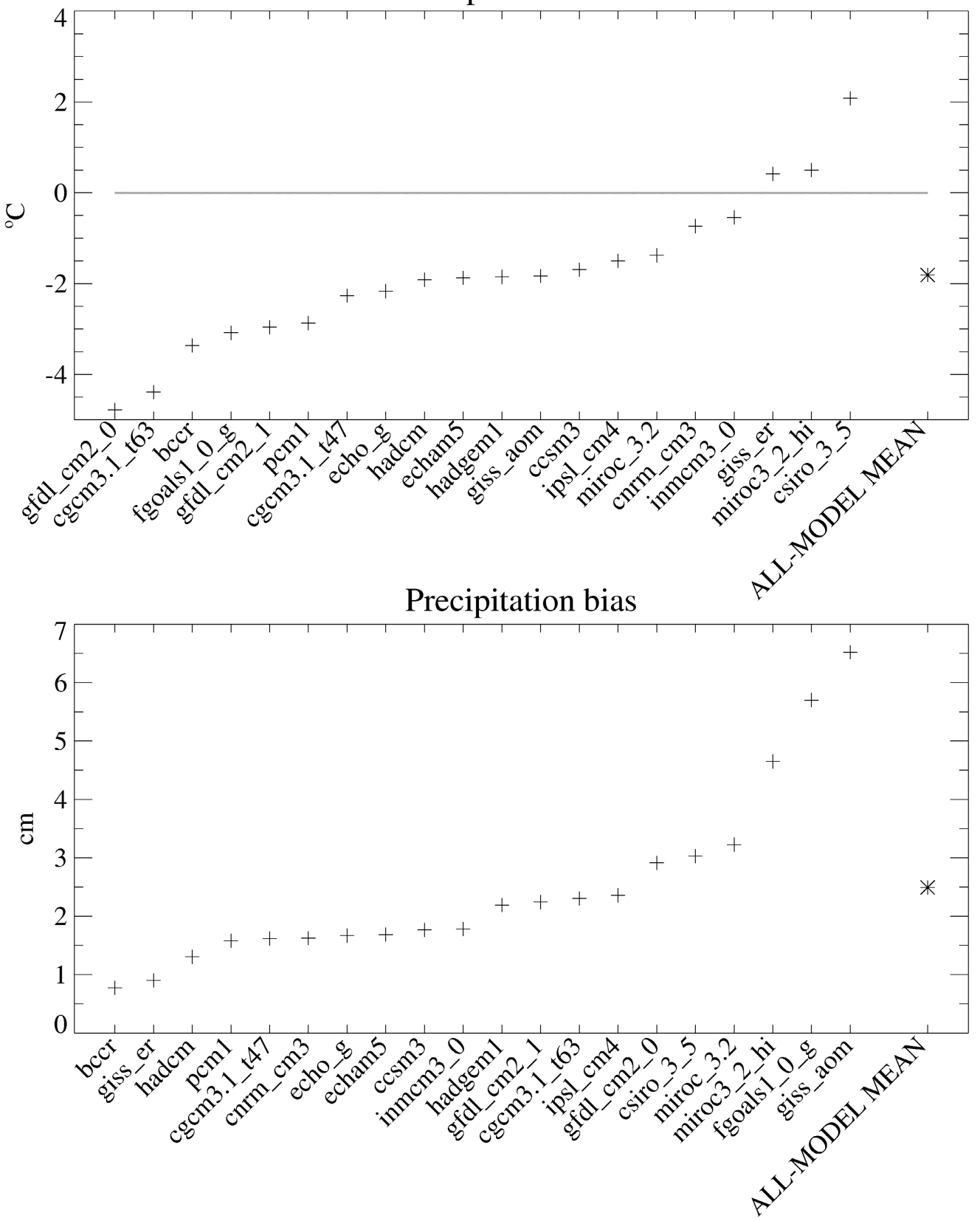

Figure 2. Differences (biases) between each model's mean annual (top) temperature and (bottom) precipitation from gridded CRU data, averaged over the Pacific Northwest, for 1970-99.

slightly lower and precipitation quite a bit higher (Mote and Salathé 2009) than the CRU averages, so the average biases were smaller and in the case of temperature the list of models with lowest bias was different.

The models' simulated seasonal cycles for the PNW are shown in Figure 3. For temperature, the multi-model average is consistently $1-3^{\circ} \mathrm{C}$ cooler than CRU for each month, and six models (led by MIROC-hi) have a lower root-mean-square (rms) difference from CRU than the multi-model average. With NCEP, the multi-model mean was consistently within $1^{\circ} \mathrm{C}$ of NCEP monthly means and no model had a smaller rms difference. 

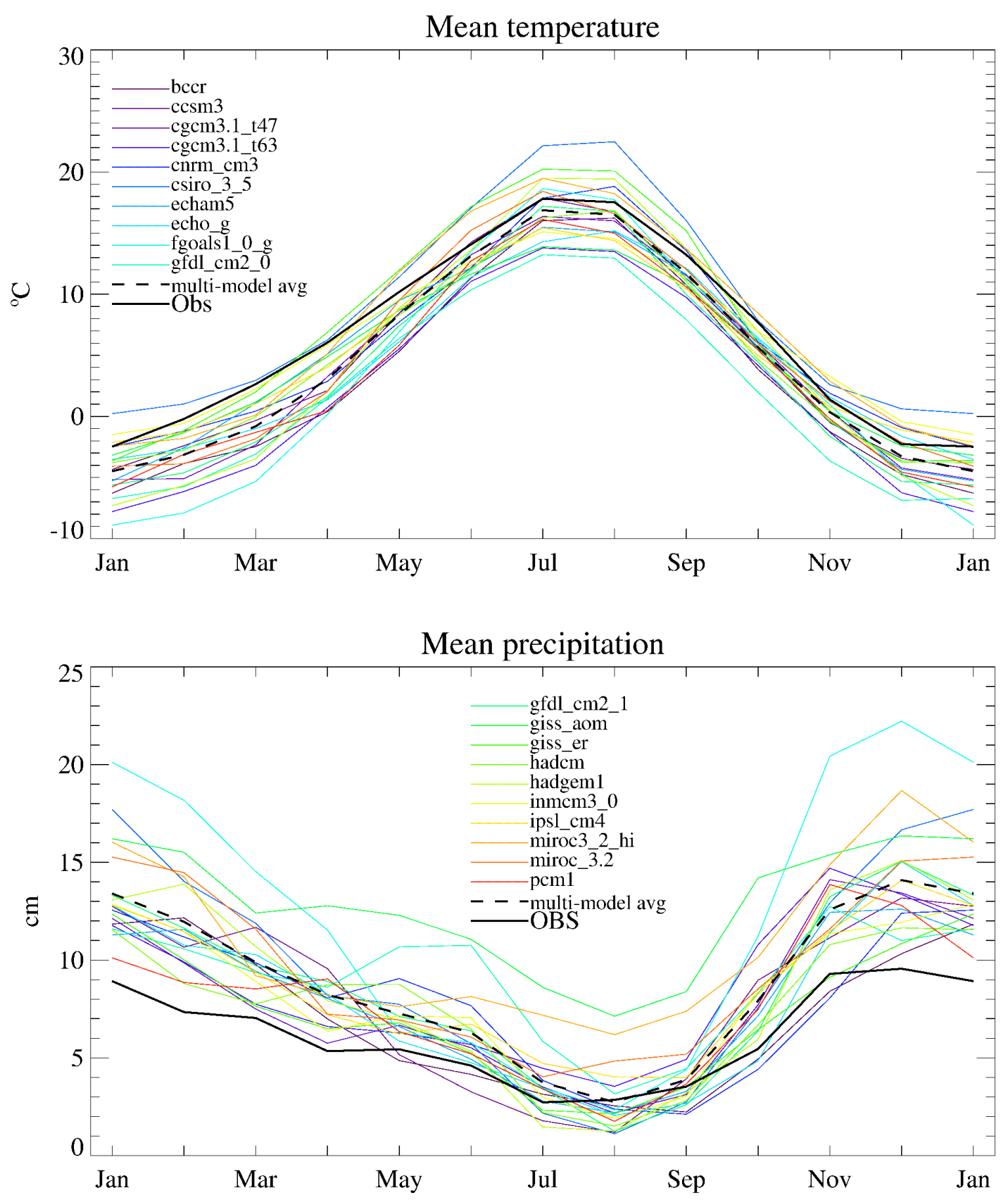

Figure 3. Mean seasonal cycle for each climate model from its 20th century simulation, compared with the CRU data (black), averaged over the PNW. All 20 models are shown in both panels but the legend is split between the panels. The black dashed line shows the average of all the models, which is quite close to the observations for temperature and a bit too wet for precipitation, but with approximately the right contrast between wet and dry seasons.
For precipitation, all models reproduce the contrast between wet winters and dry summers, though a few produce summers that are only slightly drier than winters. The multi-model average is $30-50 \%$ wetter than CRU in most months. Twelve of the models have a lower rms difference from observed than the multi-model average, with GISS_er the closest and FGOALS the farthest owing to its very wet summers.

Another facet of 20th century climate that can be evaluated is the trend in temperature. For the global average, many models simulate a warming rate similar to the $0.6^{\circ} \mathrm{C}$ increase in global temperature observed in the 20 th century. At the regional scale (Figure 4), the warming rate could be dominated by changes in atmospheric circulation rather than greenhouse forcing; nonetheless, eight of the models simulate a warming for 19002000 in the Northwest within $0.2^{\circ} \mathrm{C}$ of the observed warming of $0.8^{\circ} \mathrm{C}$ 


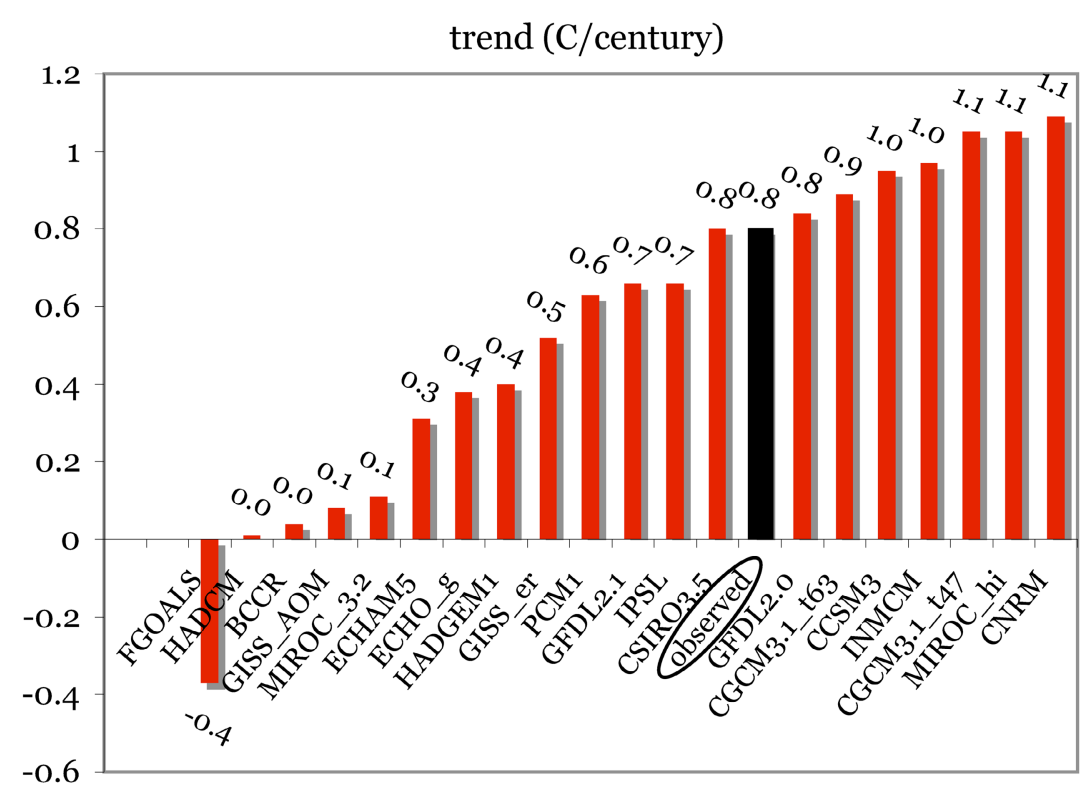

during the same period, calculated using regionally averaged, areaweighted Historical Climate Network data (Mote 2003, updated). We do not perform the same comparison for precipitation since there is no evidence that precipitation responded to greenhouse forcing in the $20^{\text {th }}$ century, either globally or in the zonal mean at these latitudes (Zhang et al. 2007). The time series of regional precipitation is characterized by high interannual variability, and the direction of linear trends depend on the start and end point, unlike temperature, for which linear trends are robustly upward.

Finally, we examine aspects of $20^{\text {th }}$ century climate that pertain to the mesoscale modeling that will be reported elsewhere (Salathé et al. 2009, this report). Since the GCMs provide the global context for the regional modeling, the GCM fields over the domain of the mesoscale model help determine the quality of the mesoscale model simulation; in particular the moisture flux into the region provided by the GCM plays a crucial role in determining both the amount and the distribution of precipitation by the regional model.

For each model, we mapped the precipitation, sea level pressure (SLP), and temperature over roughly the domain for which we ran the mesoscale model (results of which will be reported elsewhere). Figure 5 shows the maps for one of these models, the CGCM_T47, compared with the NCEP/ NCAR reanalysis. This model was chosen for display because it scores the best in comparisons with the reanalysis (Figure 6). In both instances we show the annual mean for 1950-99. All models reproduce the basic features of each field: the heavy precipitation over the coastal mountains of British Columbia, the swath of high precipitation in the lower left corner, the Aleutian low and Pacific high pressure features in the top panel, and the low temperatures over the mountainous West and the strong gradient of sea surface temperature over the eastern Pacific.

An efficient method of quantitatively comparing fields is the Taylor diagram (Taylor 2000). Values are plotted in radial coordinates with the radius being the ratio of the modeled area-averaged variance to the
Figure 4. Trend in each model's annual mean temperature for the PNW during the 20th century, and the observed trend calculated from the USHCN data. Note that the observed trend is close to the median trend from the models. 

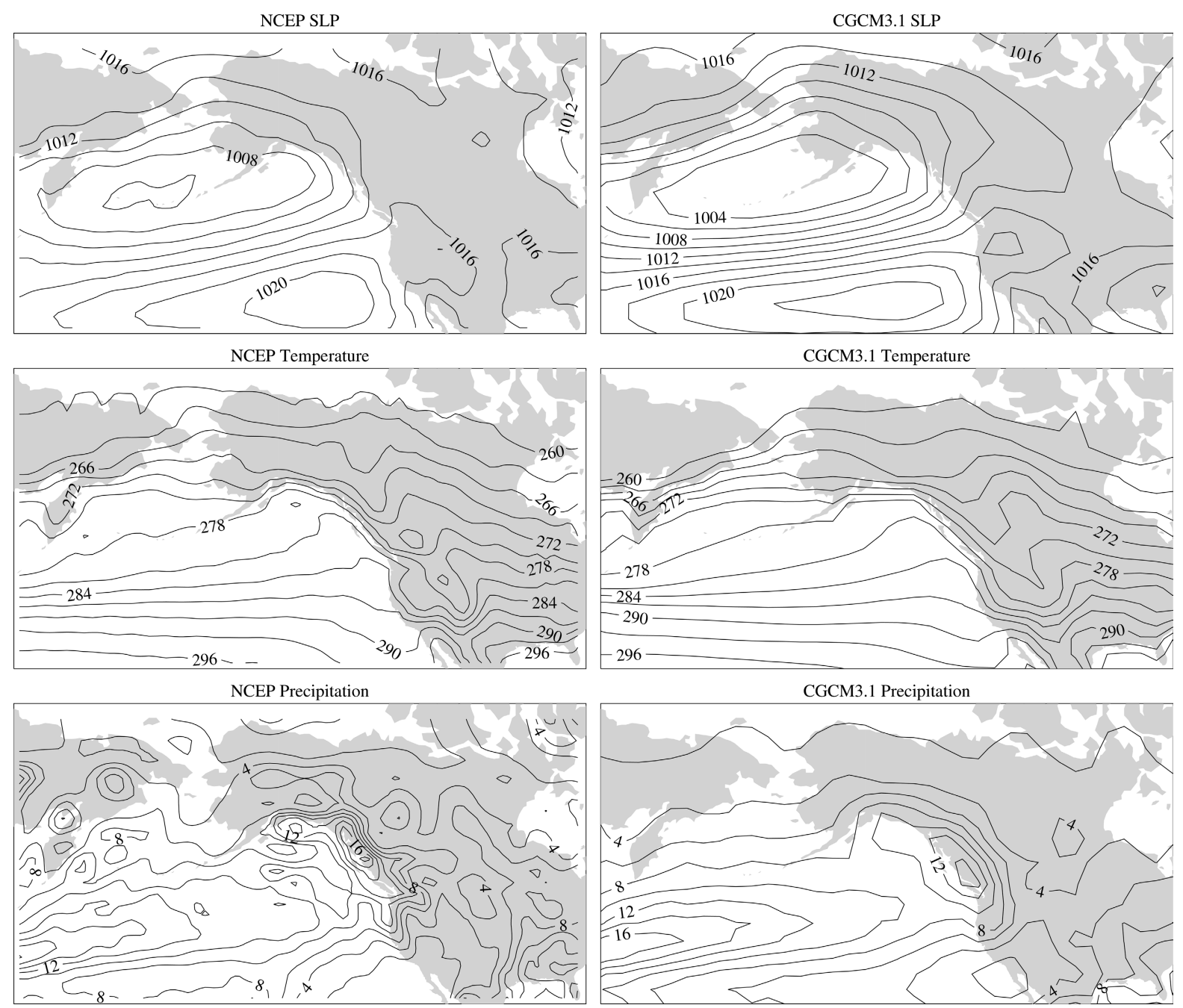

Figure 5. Annual mean patterns from (left column) CGCM-T47 and (right column) NCEP-NCAR reanalysis, for years 1950-99. Top row shows sea level pressure in $\mathrm{hPa}$, middle row temperature in Kelvin $\left(273.16 \mathrm{~K}=0^{\circ} \mathrm{C}=32^{\circ} \mathrm{F}\right)$, and bottom row precipitation in $\mathrm{mm} /$ day. observed area-averaged variance, where the variance is calculated at each grid point using 50 years (1950-99) of monthly data. The angle represents the spatial correlation between the 50-year mean fields. Figure 6 shows the Taylor diagram for all 20 models, evaluated over the domain shown in Figure 5. As with global mean fields (Randall et al. 2007), of the three fields shown here temperature is best simulated by the models, with a correlation typically $>0.97$. Sea level pressure is next best simulated, followed by precipitation, except that for GISS-ER the SLP is worse than any model's precipitation field, owing largely to an Aleutian Low that is much too far to the west. In the Taylor diagram, the distance of a point to $(1,1)$ represents the rms error, and we can use this distance to rank the models for each field and to average the distances to rank the models overall (Fig. 6 lower). Of all the models, CGCM-T47 (shown in Fig. 5) ranks the best.

\section{Projected Changes in Temperature and Precipitation}

Some years ago it was common practice in impacts research to present the results of one or two global climate models. With greater opportunities and technical abilities for analyzing multiple model simulations, ensembles are now the state of the science. Climate model simulations provide 

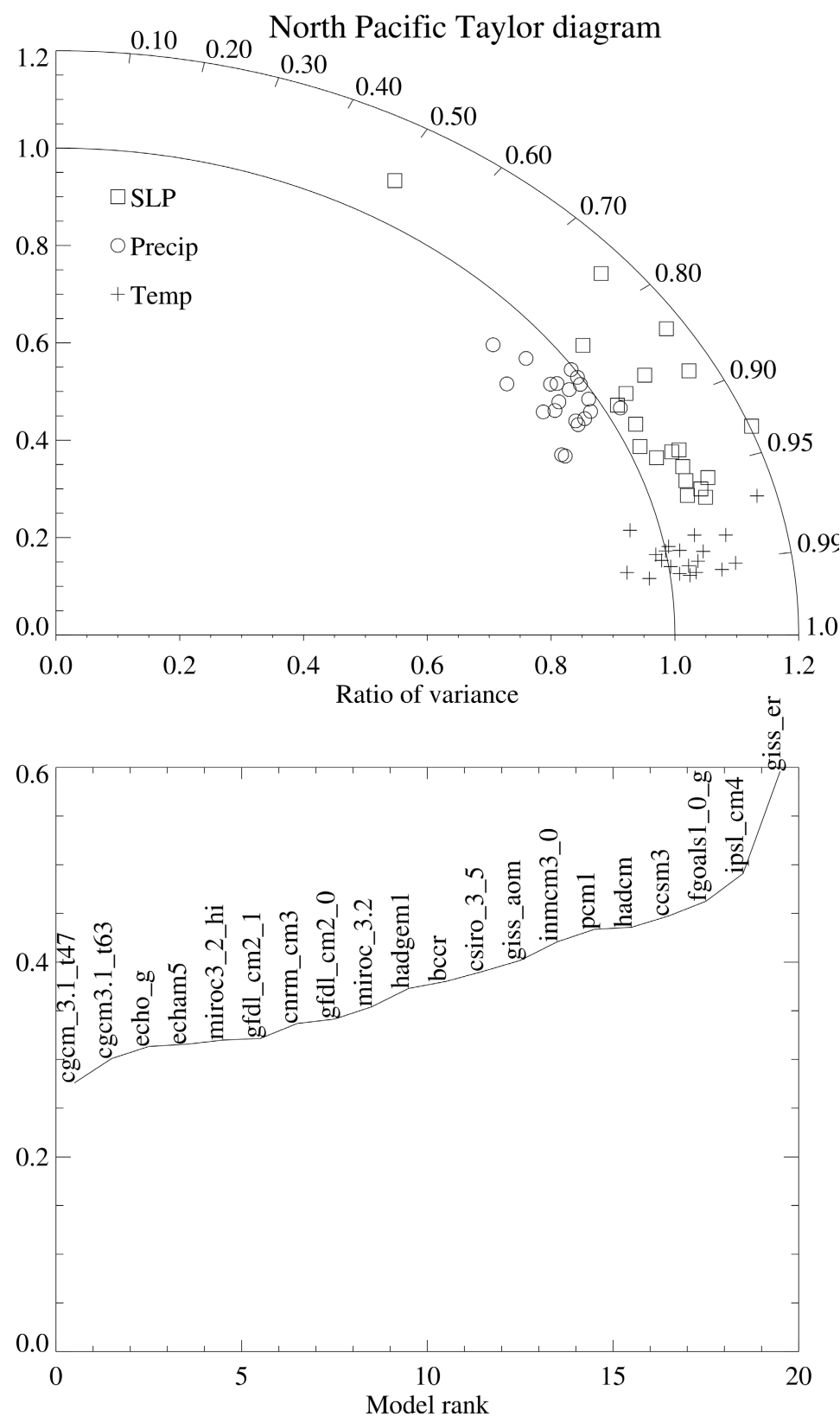

Figure 6. Evaluation of model performance over the domain shown in Figure 5. Top panel shows the correlation (angle) and ratio of variance (radius) for each model and each field. The root-mean-square difference from the observed field is just the distance on the diagram. Bottom panel ranks the models by mean distance for the three fields. Most models simulate temperature fairly well, sea level pressure less well, and precipitation still less well, but there is a wide range in performance especially for sea level pressure. The model that scores the best overall is shown in the right hand panels in Figure 5.

"ensembles of opportunity" (Meehl et al. 2007) whereas what we really need are statistical distributions of future changes - e.g., estimates of the likelihood of changes in temperature above a certain value by a certain date. It is common practice to presume that the distribution of future changes is well represented by an ensemble of future climate model projections, though massive distributed climate experiments through climateprediction.net offer one possible way to characterize statistical distributions (e.g., Stainforth et al. 2005) and the authors of this chapter are engaged in a project to produce regional climate simulations using the climateprediction.net framework. Here, we follow common practice and present the range of projected changes from model simulations as well as a weighted average.

The new, weighted average follows the reliability ensemble averaging "REA" (Giorgi and Mearns 2002) approach. In this approach, the REA value 
Figure 7. Smoothed traces in temperature (top) and precipitation (bottom) for the 20th and 21st century model simulations for the PNW, relative to the 1970-99 mean. The heavy smooth curve for each scenario is the REA value, calculated for each year and then smoothed using loess. The top and bottom bounds of the shaded area are the 5th and 95th percentiles of the annual values (in a running 10-year window) from the $\sim 20$ simulations, smoothed in the same manner as the mean value. Mean warming rates for the 21 st century differ substantially between the two SRES scenarios after 2020, whereas for precipitation the range is much wider than the trend and there is little difference between scenarios. for each season and decade is calculated by weighting each model's output by its bias and distance from the all-model average. Multi-model averages in weather forecasting, seasonal forecasting, and climate simulations often come closer to observations than single models (see Figure 3a above), and REA may produce better results for the future than an unweighted average by giving more weight to models that perform well in simulating 20th century climate. For details on the REA calculation, see Appendix B. The weights assigned to each model for the REA calculations are listed in Table 1. In this document, "2020s" denotes the 2010-2039 average, 1980s denotes the 1970-1999 average, and likewise for 2040s and 2080s.

\section{1. $21^{\text {st }}$ Century Trends in the Annual Mean}

The regionally averaged temperature and precipitation for all B1 and A1B simulations are shown in Figure 7, along with the REA value for each year. To calculate the REA weighting, each model's projected temperature is smoothed by regressing temperature on the logarithm of the atmospheric concentration of $\mathrm{CO}_{2}$, an approximation (IPCC 2001) of global radiative forcing (see Figure 1). The same is done for precipitation. This approach,
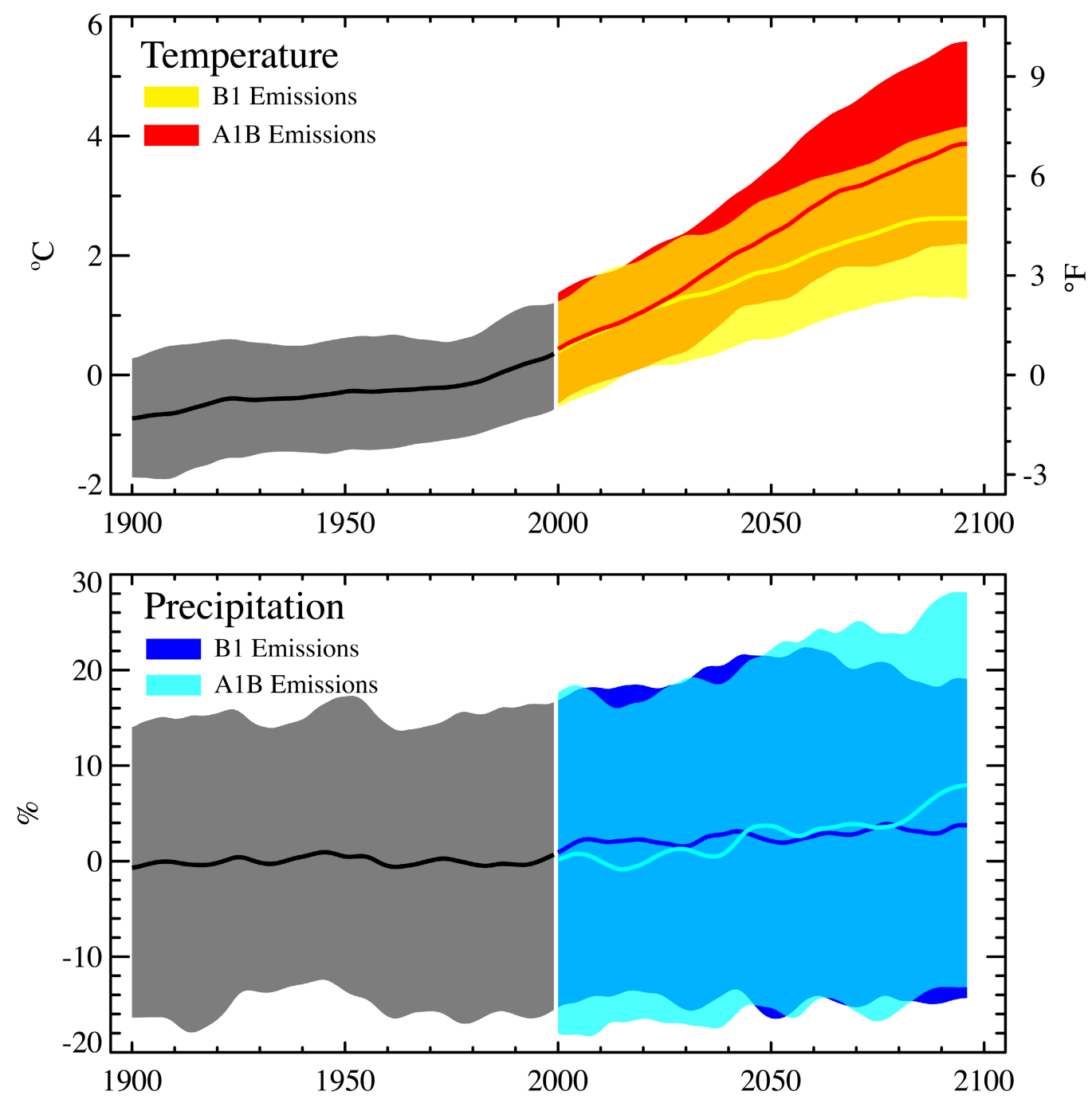
which is used only to calculate the annual REA values shown in Figure 7 , highlights the region's response to the forcing on century timescales, masking model interdecadal variability which, while interesting, can confound the detection of forced change, especially for precipitation. Note how different the evolution of temperature is after about 2050 for the two scenarios, owing to the markedly different radiative forcing produced by different concentrations of greenhouse gases. By the 2080s the REA value of temperature change is almost $3.4^{\circ} \mathrm{C}\left(6.1^{\circ} \mathrm{F}\right)$ for $\mathrm{A} 1 \mathrm{~B}$ and only $2.5^{\circ} \mathrm{C}$ $\left(4.5^{\circ} \mathrm{F}\right)$ for $\mathrm{B} 1$. The range just for these two scenarios is 1.5 to $5.8^{\circ} \mathrm{C}(2.8$ $9.7^{\circ} \mathrm{F}$ ); other IPCC emissions scenarios would produce more warming by 2100 , but B1 produces the least.

The observed trend in regional mean temperature is statistically significant, that is, it exceeds what would be expected from a time series with no trend and the same amount of interannual variability (Mote 2003). Likewise, the projected future trends, even for the very lowest of the scenarios, is substantially greater than observed in the $20^{\text {th }}$ century.

Model results for changes in precipitation are equivocal (Figure 7). In the maps of late- $21^{\text {st }}$ century changes in precipitation presented by Christensen et al. (2007), nearly all climate models project increases in annual mean precipitation in the northern third of North America and nearly all project decreases in the southern third, and the PNW lies in the vague area in between. Consistent with those maps, the annual mean REA change for the PNW is practically zero throughout the $21^{\text {st }}$ century, though individual models produce changes of as much as $-10 \%$ or $+20 \%$ by the 2080 s. It should be noted that the REA weighting emphasizes past performance and

Table 1. REA weights (bias factor times distance factor) for the A1B scenario. Seasonal weights are computed separately and do not sum to the total.

\begin{tabular}{|c|c|c|c|c|c|c|c|c|c|c|}
\hline & \multicolumn{5}{|c|}{ Temperature } & \multicolumn{5}{|c|}{ Precipitation } \\
\hline & DJF & MAM & JJA & SON & annual & DJF & MAM & JJA & SON & annual \\
\hline becr & 0.2 & 0.3 & 0.3 & 0.3 & 0.2 & 1.0 & 1.0 & 1.0 & 1.0 & 0.9 \\
\hline $\operatorname{ccsm} 3$ & 0.3 & 0.5 & 1.0 & 0.4 & 0.4 & 1.0 & 1.0 & 1.0 & 1.0 & 1.0 \\
\hline cgcm3.1_t47 & 0.2 & 0.4 & 0.5 & 0.5 & 0.3 & 1.0 & 1.0 & 0.7 & 1.0 & 0.4 \\
\hline cgcm3.1_t63 & 0.1 & 0.2 & 0.2 & 0.2 & 0.1 & 1.0 & 1.0 & 1.0 & 1.0 & 1.0 \\
\hline cnrm_cm 3 & 1.0 & 0.5 & 1.0 & 1.0 & 0.9 & 1.0 & 1.0 & 1.0 & 1.0 & 0.7 \\
\hline csiro_3_5 & 0.2 & 1.0 & 0.2 & 0.6 & 0.3 & 1.0 & 1.0 & 1.0 & 1.0 & 1.0 \\
\hline echam 5 & 0.2 & 1.0 & 0.3 & 0.4 & 0.3 & 0.8 & 1.0 & 1.0 & 1.0 & 0.9 \\
\hline echo g & 0.6 & 0.3 & 0.2 & 1.0 & 0.3 & 1.0 & 1.0 & 0.6 & 0.7 & 0.5 \\
\hline fgoals1_0_g & 0.1 & 0.2 & 1.0 & 0.6 & 0.2 & 1.0 & 1.0 & 1.0 & 1.0 & 1.0 \\
\hline gfdl_cm $2 \_0$ & 0.1 & 0.3 & 0.1 & 0.1 & 0.1 & 1.0 & 1.0 & 0.7 & 1.0 & 0.7 \\
\hline gfdl_cm2_1 & 0.2 & 0.3 & 0.5 & 0.2 & 0.2 & 1.0 & 1.0 & 1.0 & 1.0 & 1.0 \\
\hline giss_aom & 0.8 & 1.0 & 0.2 & 0.4 & 0.4 & 1.0 & 1.0 & 0.4 & 0.6 & 0.3 \\
\hline giss_er & 0.5 & 1.0 & 0.2 & 1.0 & 1.0 & 0.4 & 0.6 & 0.6 & 0.5 & 0.2 \\
\hline hadcm & 0.3 & 0.6 & 0.4 & 0.3 & 0.3 & 1.0 & 1.0 & 0.4 & 0.6 & 0.4 \\
\hline hadgem1 & 0.1 & 0.3 & 0.6 & 1.0 & 0.4 & 0.4 & 0.7 & 0.4 & 0.5 & 0.2 \\
\hline inmcm3_0 & 0.6 & 1.0 & 0.3 & 1.0 & 1.0 & 1.0 & 1.0 & 0.6 & 0.9 & 0.4 \\
\hline ipsl_cm $\overline{4}$ & 1.0 & 0.8 & 0.3 & 0.4 & 0.4 & 1.0 & 1.0 & 1.0 & 1.0 & 0.5 \\
\hline miroc3_2_hi & 1.0 & 1.0 & 0.4 & 0.8 & 1.0 & 0.5 & 0.8 & 0.7 & 0.9 & 0.2 \\
\hline miroc_ $3 . \overline{2}$ & 0.3 & 0.4 & 1.0 & 0.7 & 0.5 & 0.5 & 1.0 & 1.0 & 0.8 & 0.3 \\
\hline pcm 1 & 0.2 & 0.3 & 0.3 & 0.4 & 0.2 & 1.0 & 1.0 & 0.6 & 1.0 & 0.4 \\
\hline
\end{tabular}


2020s
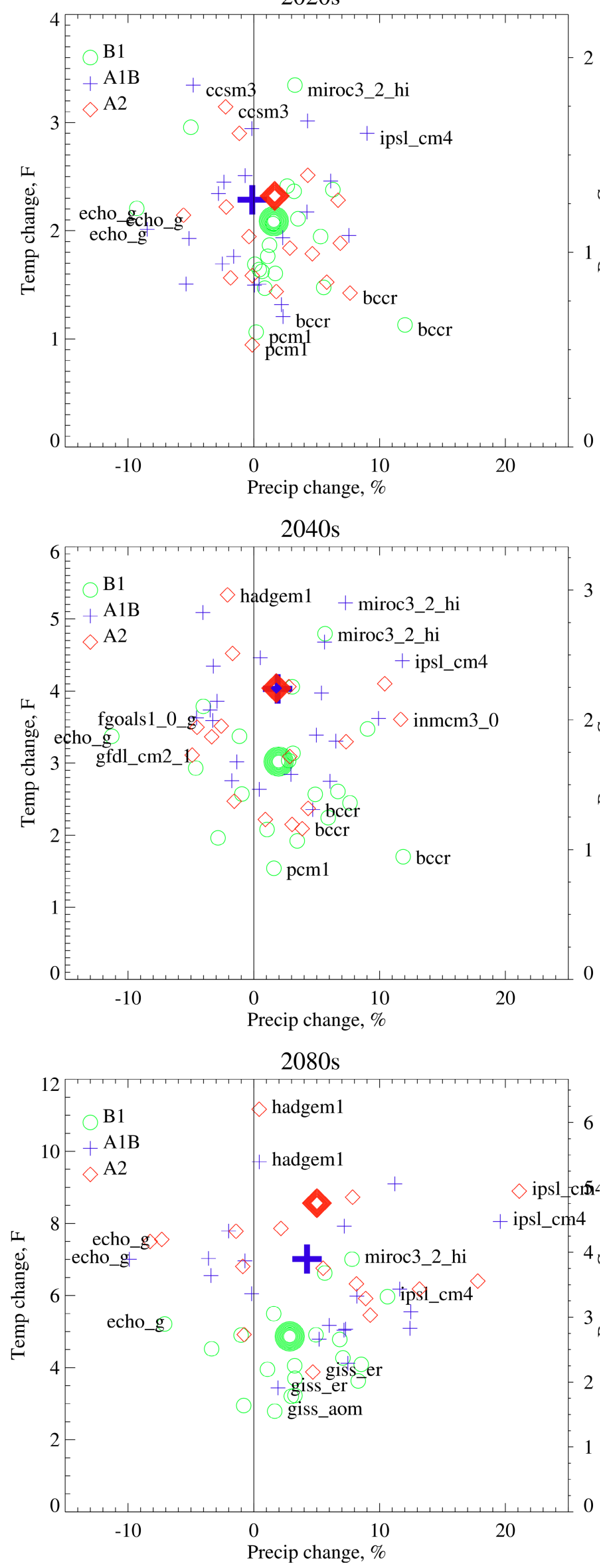

Figure 8. Scatterplot of change in annually averaged PNW temperature and precipitation for each of the 20 models and 3 SRES scenarios, for the decades indicated. Green circles indicate $B 1$, blue crosses $A 1 B$, and red diamonds A2. Large bold symbols indicate the REA value for each scenario and decade. Model names label the four extremes for each scenario. 
closeness to the multi-model mean, which are no guarantee of responding correctly to future greenhouse forcing; but it could also be argued that the models with poor performance in simulating observed annual mean or seasonal precipitation may have the storm track at the wrong latitude and hence respond incorrectly to future greenhouse forcing.

Another way to view the scenarios is to plot the change in temperature on one axis and the change in precipitation on another axis (Figure 8). Figure 8 roughly shows the sensitivity of the models to forcing, with different magnitudes of forcing applied by the three SRES scenarios and in different quantities for the three decades. The ranking of models is similar for each decade and SRES scenario: HadGEM1, MIROC3_2_hi, or CCSM3 tend to be the warmest in each scenario and each decade, IPSL_CM4 or BCCR the wettest, and so on. Unlike the situation in the global mean, where the precipitation change and temperature change of models tend to be correlated, there seems to be no correspondence between temperature change and precipitation change in the Pacific Northwest. Differences among the scenarios are small in the 2020s but are substantial by the $2040 \mathrm{~s}$. In the coolest scenario, regional temperature rises $0.6^{\circ} \mathrm{C}\left(1.1^{\circ} \mathrm{F}\right)$ by the $2020 \mathrm{~s}, 0.9^{\circ} \mathrm{C}\left(1.5^{\circ} \mathrm{F}\right)$ by the $2040 \mathrm{~s}$, and $1.6^{\circ} \mathrm{C}\left(2.8^{\circ} \mathrm{F}\right)$ by the $2080 \mathrm{~s}$. In the warmest scenario, annually averaged warming is roughly a factor of three higher than the lowest scenario: $1.9^{\circ} \mathrm{C}\left(3.3^{\circ} \mathrm{F}\right)$ by the $2020 \mathrm{~s}, 2.9^{\circ} \mathrm{C}$ $\left(5.2^{\circ} \mathrm{F}\right)$ by the $2040 \mathrm{~s}$, and $5.4^{\circ} \mathrm{C}\left(9.7^{\circ} \mathrm{F}\right)$ by the $2080 \mathrm{~s}$.

\subsection{Seasonality of Changes in Climate}

For some applications the changes of climate in a given season may be more important than the changes in annual mean. In this section we present the changes in climate by season. Figures 9 and 10 show changes in temperature and precipitation for the 2020s, 2040s, and 2080s relative to the 1980s. For both B1 and A1B, warming is projected to be largest in summer. In most seasons $\mathrm{B} 1$ has the lowest projected change and $\mathrm{A} 1 \mathrm{~B}$ the highest, but this is not always true in the 2020s when the radiative forcing of the two scenarios is very similar.

On the seasonal scale the most consistent changes in precipitation appear in the summertime, with a large majority of models (68-90\% depending on decade and SRES scenario) projecting decreases and the REA value reaching $-14 \%$ by the 2080 s. Some models foresee reductions of as much as $20-40 \%$ in summer precipitation, though these large percentages only translate to 3- $6 \mathrm{~cm}$ over the season, $3-6 \%$ of the all-model annual mean $20^{\text {th }}$ century value $(102 \mathrm{~cm})$. While small hydrologically in the Northwest, summer precipitation and its associated cloudiness nonetheless has an impact on evaporative demand and hence, for example, on urban water use (Palmer and Hahn 2002) and forest fires (McKenzie et al. 2004).

In winter, by contrast, a majority (50-80\% depending on decade and SRES scenario) of models project increases in precipitation. The REA value reaches $+8 \%$ (about $3 \mathrm{~cm}$ ) by the 2080 s for the A1B scenario, still small relative to interannual variability. And although some of the models predict modest reductions in fall or winter precipitation, some predict very large increases (up to $42 \%$ ). Changes of this magnitude would substantially alter regional hydrology. 
Figure 9. Range (lowest to highest) of projected changes in temperature for each season (DJF=winter, etc.), relative to the 1970-99 mean. In each pair of box- and-whiskers, the left one is for SRES scenario B1 and the right is A1B; circles are individual model values. Box-and-whiskers plots indicate 10th and 90th percentiles (whiskers), 25th and 75th percentiles (box ends), and median (solid middle bar) for each season and scenario. Not all values are visible due to symbol overlap. Printed values are the weighted Reliability Ensemble Average of all GCMs for the season and scenario.
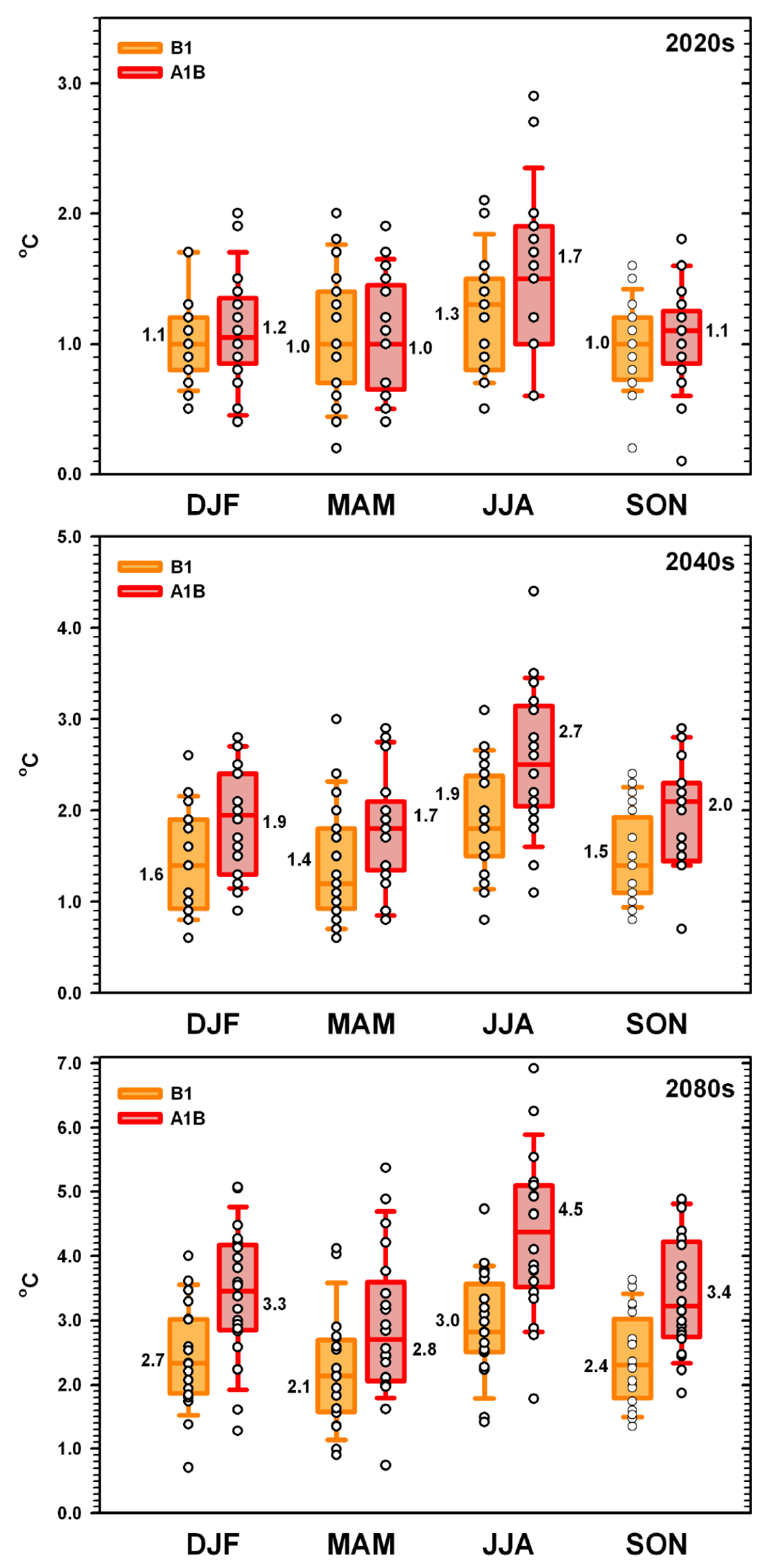

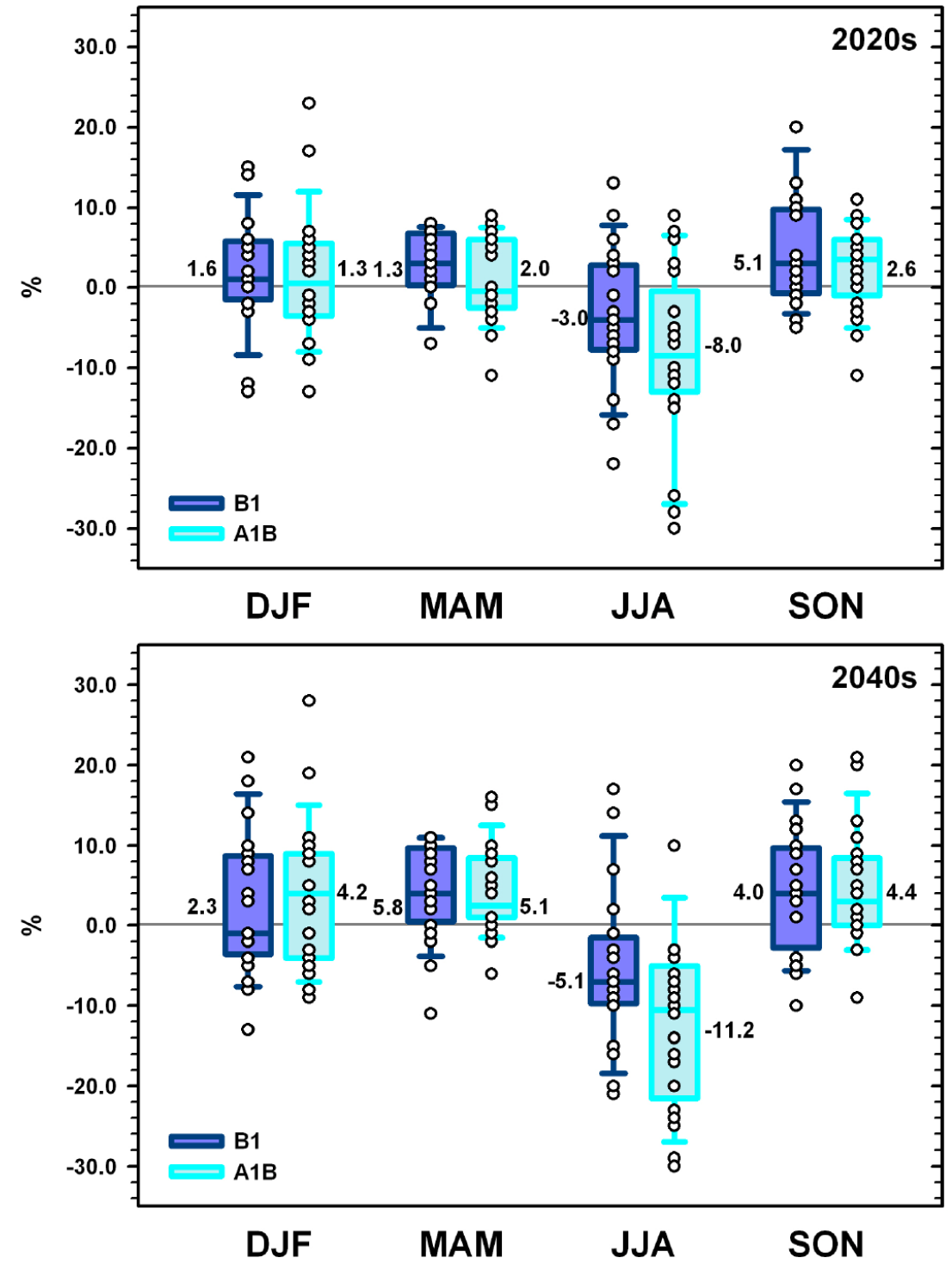

Figure 10. As in Figure 9, but for precipitation. The height of the bars indicates actual water precipitation but the percentages are calculated with respect to a reference value for that season, so that $-11 \%$ in JJA is much less than $-11 \%$ in DJF. The reference values for the extremes are that model's 20th century mean for that season (or annual mean), and for the REA average the reference is the all-model 20th century value. Unlike for temperature, for any season some models project increases and some project decreases, though the vast majority project decreases for summer and increases for winter by the 2080s 
Figure 11. Simulated annual cycle of sea surface temperature (SST) averaged over 1970-99 for all available models. Grey shading represents \pm 1 standard deviation of the multimodel ensemble about the 1970-99 mean, shown as a solid black line, and the three curves above the grey shaded area show the means for 20302059 for the three scenarios. Though small, the $1.2^{\circ} \mathrm{C}$ warming is substantially outside the 20th century variability.

Figure 12. As in Fig. 11 but for alongshore wind stress, which changes very little in the future scenarios.
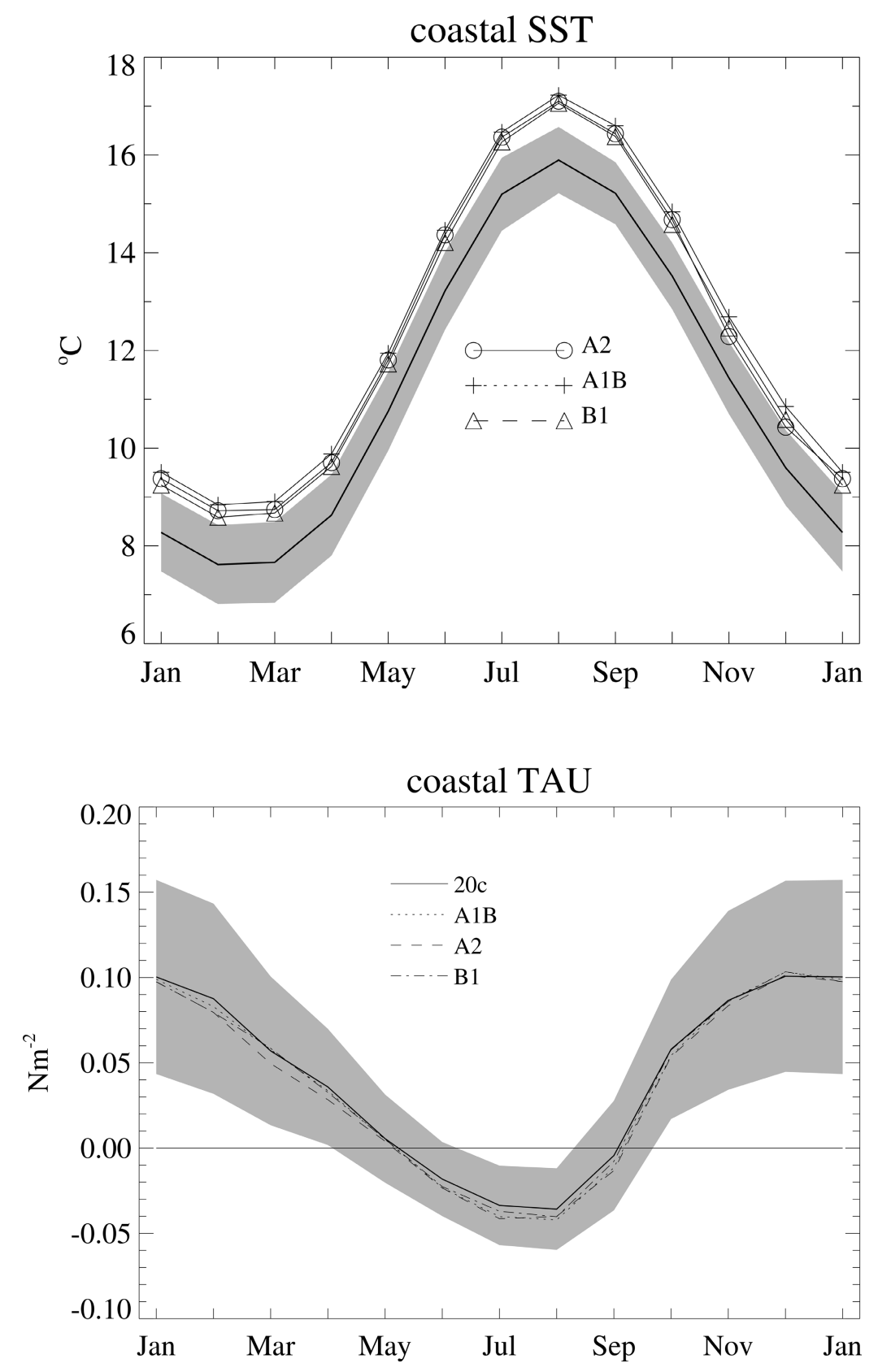

For some applications one may want to choose a few GCM scenarios to represent a "medium" (closest to REA average), "worst case", and "best case". The worst and best case will depend very much on application, and certain seasons may matter most. For example, the worst case scenario might be the one with the largest winter or spring warming and small or negative change in winter precipitation: for 2040s, MIROC $3.2 \mathrm{~A} 1 \mathrm{~B}$ has $2.8^{\circ} \mathrm{C}\left(5.0^{\circ} \mathrm{F}\right)$ spring warming, only $3 \%$ increase in spring precipitation and no change in winter precipitation. The best case may be BCCR-B1 with a $17 \%$ increase in winter precipitation, $8 \%$ increase in spring precipitation, and warming of only $0.9^{\circ} \mathrm{C}\left(1.6^{\circ} \mathrm{F}\right)$ in winter and $0.5^{\circ} \mathrm{C}\left(0.9^{\circ} \mathrm{F}\right)$ in spring. Another dimension of impacts centers on how warm-dry summers are: the mean is $+2.1^{\circ} \mathrm{C}\left(3.8^{\circ} \mathrm{F}\right)$ and $-12 \%$ for $\mathrm{A} 1 \mathrm{~B}$, worst-case $+4.4^{\circ} \mathrm{C}\left(7.9^{\circ} \mathrm{F}\right)$ and $-30 \%$ in $\mathrm{HadCM}$, and best-case $+0.85^{\circ} \mathrm{C}\left(1.5^{\circ} \mathrm{F}\right)$ and $+7 \%$ for PCM1 B1. 


\section{Changes in Coastal Water Properties}

Coastal sea surface temperature (SST) helps determine the biological and physical conditions of the marine environment and the estuaries of the Northwest. Each of the 20 models examined here has a detailed ocean model with higher spatial resolution than the atmosphere model, and simulates SST. Owing however to the still relatively coarse resolution of the ocean model and the complexity of nearshore circulations, simulated coastal SST and especially its seasonal cycle may bear little resemblance to observed SST. Figure 11 shows the mean annual cycle for the 1970-99 and 2030-59 periods for coastal grid points between $46^{\circ}$ and $49^{\circ} \mathrm{N}$. Modeled change in SST is about $1.2^{\circ} \mathrm{C}\left(2.2^{\circ} \mathrm{F}\right)$, somewhat less than for the PNW land areas $\left(2.0^{\circ} \mathrm{C}, 3.6^{\circ} \mathrm{F}\right)$ but a significant change relative to the small interannual variability of the ocean.

Along the west coast of each continent, summertime equatorward winds pull water offshore and water must upwell from depth to replace it. This nutrient-rich water serves as the basis for very high biological productivity. Our earlier analysis of two climate models (Mote and Mantua 2002) indicated little change in coastal upwelling in any of the major regions of upwelling. For the 20 models used in this study, the mean change is also quite small (Figure 12).

Another important aspect of change in the coastal ocean is local sea level rise (SLR), which is produced by the combined effects of global sea level rise and local factors such as vertical land deformation (e.g., tectonic movement, isostatic rebound) and seasonal ocean elevation changes due to atmospheric circulation effects. We previously (Mote et al. 2008) reviewed available projections of these factors for the coastal waters of Washington and provided low, medium, and high estimates of local SLR for 2050 and 2100. These are summarized here.

The Fourth Assessment Report of the IPCC projects global SLR over the course of this century to be between 18 and $38 \mathrm{~cm}$ (7-15") for their lowest (B1) emissions scenario, and between 26 and $59 \mathrm{~cm}$ (10-23") for their highest emissions scenario. Based on the current science, our "medium" estimate of $21^{\text {st }}$ century SLR in Washington is that in Puget Sound, local SLR will closely match global SLR. On the northwest Olympic Peninsula, very little relative SLR will be apparent due to rates of local tectonic uplift that currently exceed projected rates of global SLR. On the central and southern Washington coast, the number of continuous monitoring sites with sufficiently long data records is small, adding to the uncertainty of SLR estimates for this region. Available data points suggest, however, that uplift is occurring in this region, but at rates lower than that observed on the NW Olympic Peninsula.

The application of SLR estimates in decision making will depend on location, time frame, and risk tolerance. For decisions with long timelines and low risk tolerance, such as coastal development and public infrastructure, users should consider low-probability high-impact estimates that take into account, among other things, the potential for higher rates of SLR driven by recent observations of rapid ice loss in Greenland and Antarctica, which though observed were not factored into the IPCC's latest global SLR estimates. Combining the IPCC high emissions scenario 
with 1) higher estimates of ice loss from Greenland and Antarctica, 2) seasonal changes in atmospheric circulation in the Pacific, and 3) vertical land deformation, a low-probability high-impact estimate of local SLR for the Puget Sound Basin is $55 \mathrm{~cm}$ (22") by 2050 and $128 \mathrm{~cm}$ (50") by 2100. Low-probability, high impact estimates are smaller for the central and southern Washington coast (45 cm [18"] by 2050 and $108 \mathrm{~cm}$ [43"] by 2100), and even lower for the NW Olympic Peninsula (35 cm [14"] by 2050 and $88 \mathrm{~cm}$ [35"] by 2100) due to tectonic uplift.

\section{Downscaling Methods}

Two approaches are commonly used to map coarse-scale climate model output to finer-scale local detail: statistical downscaling and regional modeling. Statistical downscaling methods use the empirical relationship between an observed climatology, say precipitation, at the higher resolution and coarse-scale model fields, like the altitude of the $700 \mathrm{hPa}$ pressure level, from global climate models. The empirical relationship is derived using the observations as predictand and a simulation from a global climate model for the observed period, and may use a number of modeled fields as predictors in the empirical relationship. For example, often atmospheric circulation and moisture variables are used to downscale regional precipitation.

For this project, we applied statistical downscaling based on 1/16-degree gridded historic observed temperature and precipitation (Elsner et al. 2009, this report) using two methods. The first is a simple "delta method" where the observed daily temperature and precipitation from the period 19701999 are perturbed to produce fine-scale projections of the future (e.g. Loáiciga 2000; Lettenmaier and Gan 1990), by computing monthly mean changes in average PNW temperature and percent change in precipitation for the 2020s, 2040s, and 2080s. We then apply these perturbations, or deltas, to the 1/16-degree historic data to form future climate change scenarios. At each grid point, the regional temperature delta is added to the observed daily maximum and minimum temperatures and the regional precipitation delta is multiplied by the daily precipitation. In this way, we produce 30-year daily temperature and precipitation sequences and spatial patterns that are physically consistent but modified by different scenarios of climate change for each future time period and each global climate model. This method has the advantage of preserving the observed sequence of weather and natural climate variability, which allows easy comparison to the past. However, if anthropogenic influence on climate includes a change in higher statistical moments - variance, skewness - this method will miss such changes.

The second and more sophisticated statistical downscaling method is based on methods described by Wood et al. (2002), Widmann et al. (2003), and Salathé (2005). This approach preserves the observed statistical properties of temperature and precipitation during the $20^{\text {th }}$ century while allowing these to change in future projections. As in Wood et al., the monthly-mean global climate model data are bias-corrected. The bias-corrected climate model is then downscaled to 1/16-degree grid spacing. For precipitation, the "dynamical scaling" method presented in Widmann et al. (2003) is used. This method accounts for the effects of both large-scale precipitation 
processes and changes in atmospheric circulation on the local precipitation. For temperature, a simple spatial disaggregation is applied (Wood et al. 2002). Finally, the monthly mean data are disaggregated to daily time steps using the method described in Salathé (2005).

The important differences between the transient statistical downscaling and delta method are 1) the trends in the climate projection are preserved and 2) modes of climate variability and shifts in climate variability in the global model are preserved in the transient downscaling. In some applications, for example in water resource planning, these issues are not important and make the interpretation of results more difficult (Salathé et al. 2007). In other applications, for example in modeling ecologic systems, climate trends and variability are important to consider.

Regional climate models are another tool for downscaling and provide a physically-based representation of the interactions between the large-scale atmospheric features simulated by global models and the fine-scale regional features such as terrain, land-use, and water bodies. These interactions can produce local rates of change of temperature and precipitation that are quite different from those simulated by global climate models (Salathé et al. 2008). Salathé et al (2009) present results from a regional climate model applied to downscale two global climate models.

The relative merits of downscaling methods for the Pacific Northwest are discussed in Salathé et al. (2007). Statistical downscaling has an important advantage over a regional model in that it is computationally efficient and allows the consideration of a large set of climate scenarios. Over the next 50 years, projections differ much more among various models than among emissions scenarios. Therefore, to fully account for this uncertainty, a multi-model ensemble is the most appropriate approach and statistical downscaling is well suited to many applications that require projections only of temperature and precipitation. Statistical methods can also tune the statistical properties of climate simulations, eliminating biases and adjusting the variance, to better match observed statistics. Regional climate models, however, can better represent the local responses to climate change, which may be critical to applications in regions of complex terrain and land-water contrasts. Regional simulations also open up a broad range of impacts applications that are not suited to statistical downscaling, such as air quality modeling (Avise et al. 2006).

\section{Discussion and Conclusions}

Most GCMs reproduce key features of observed PNW climate including the sharp contrast between wet winters and dry summers, the $20^{\text {th }}$ century warming of about $0.8^{\circ} \mathrm{C}$, and the mean atmospheric circulation over the North Pacific. These successes provide some confidence in their projected changes in future climate. For the SRES scenarios examined here, all models produce annual mean warming of at least $0.1^{\circ} \mathrm{C}$ per decade with some prospect of stabilizing climate by 2100 in the B1 scenario. For the A1B scenario the warming by the 2080 s could be as high as $5.7^{\circ} \mathrm{C}\left(9.7^{\circ} \mathrm{F}\right)$ according to one model. Even the mean warming rate of $0.3^{\circ} \mathrm{C}\left(0.5^{\circ} \mathrm{F}\right)$ per decade could produce profound changes in the hydrology and environment of the Northwest, as discussed in later chapters. 
Annual mean precipitation changes little when averaged over all the models, but individual models produce substantially wetter or drier futures. For all of the 30-year means considered here, a majority of models produce wetter winters and drier summers, though the average shifts are small and not statistically significant.

Changes in the coastal zone include large projected warming relative to $20^{\text {th }}$ century variability but little change in coastal along-shore wind stress and coastal upwelling.

Other important aspects of climate change are more suitable for investigation by regional models, which can better resolve daily-scale as well as fine spatial-scale variability. Leung et al. (2004) using a regional model forced by an earlier version of the PCM found reductions (not significant) in precipitation west of the Cascades, especially in winter, but increases throughout the PNW in extreme daily precipitation. Salathé et al. (2009, this report) provide additional analysis of changes at smaller scales.

\section{Acknowledgments}

We are grateful to the Program for Climate Model Diagnosis and Intercomparison for making available the model output, and to the State of Washington for funding this work. Emily Jump assisted in processing the GCM output.

\section{Appendices}

\section{Appendix A}

In a few instances the data available from Run 1 appeared not to be complete (e.g., missing variable or decade) so we used Run 2. The models for which this occurred were CCSM3 A2 and B1, and PCM1 B1.

\section{Appendix $B$}

Reliability ensemble averaging (REA) uses a bias factor and a distance factor to weight each model's output. Each factor is calculated by averaging quantities over the Pacific Northwest, for each season and for the annual mean, following these steps.

1. Compute the difference $\delta$ between the model mean and CRU mean, for the 1970-99 period.

2. Calculate the tolerance factor $\varepsilon$ to allow for variability of 30 -year means relative to the century timescale. First, using regionally averaged CRU data for 1901-2000, detrend (subtract the linear fit from) the $20^{\text {th }}$ century time series, then calculate the standard deviation $\varepsilon$ of the running 30 -year mean. The tolerance factor is used in computing both the bias factor and the distance factor.

3. Calculate the bias factor. For models with a $\delta$ less than $\varepsilon$, the bias factor is 1 ; if $\delta$ is greater than $\varepsilon$, the bias factor is reduced to $\varepsilon / \delta$.

4. Looking now at $21^{\text {st }}$ century simulations, regress the quantity in question (e.g., annual mean temperature) on the $\log$ of $\mathrm{CO}_{2}$ (see Figure 1). For purposes of calculating the distance factor, take the 
value of the resulting fit at year 2045 minus the value at year 2000, $\mathrm{di}$, for model $\mathrm{i}$. This is the only step in which we depart from the method of Giorgi and Mearns, and we do so in order that each model has a single weighting factor for each of the time periods considered (2020s, 2040s, 2080s).

5. Calculate the all-model mean value $\mathrm{d}$ of the individual model distances $d_{i}$. Then weight each model $d_{i}$ by its distance from the mean $\mathrm{d}$ and recompute the all-model mean $\mathrm{d}$. Only one or two iterations is needed to converge.

6. Calculate the distance factor in the same manner as the bias factor: for di less than $\varepsilon$, the distance factor is 1 ; for $\mathrm{d}_{\mathrm{i}}$ greater than $\varepsilon$, the distance factor is $\varepsilon / \mathrm{d}_{\mathrm{i}}$.

7. For each season, decade, scenario, and variable, compute an REA value by summing over all available models the product of the model's projected change, its bias factor, and its distance factor.

\section{References}

Cayan DR, Maurer EP, Dettinger MD, Tyree M, Hayhoe K (2007) Climate change scenarios for the California region. Clim Chang, doi 10.1007/s10584-007-9377-6

CCSP (2008) Climate Models: An Assessment of Strengths and Limitations. A Report by the U.S. Climate Change Science Program and the Subcommittee on Global Change Research [Bader D.C., C. Covey, W.J. Gutowski Jr., I.M. Held, K.E. Kunkel, R.L. Miller, R.T. Tokmakian and M.H. Zhang (Authors)]. Department of Energy, Office of Biological and Environmental Research, Washington, D.C., USA, $124 \mathrm{pp}$

Christensen JH, et al. (2007) Regional climate projections. In: Climate Change 2007: The physical science basis. Contribution of working group I to the fourth assessment report of the Intergovernmental Panel on Climate Change [Solomon S, Qin D, Manning M, Chen Z, Marquis M, Averyt KB, Tignor M, Miller HL (eds.)]. Cambridge University Press, Cambridge, United Kingdom and New York, NY, USA

Elsner MM, Cuo L, Voisin N, Hamlet AF, Deems JS, Lettenmaier DP, Mickelson KEB, Lee SY (2009) Implications of 21st century climate change for the hydrology of Washintgon State. Clim Chang, in preparation

Giorgi F, Mearns LO (2002) Calculation of average, uncertainty range, and reliability of regional climate changes from AOGCM simulations via the reliability ensemble averaging (REA) method. J Clim 15: 1141-1158

Hamlet AF, Lettenmaier DP (2005) Production of temporally consistent gridded precipitation and temperature fields for the continental United States. J Hydrometeorol, 6: 330-336

Kalnay E, et al. (1996) The NCEP/NCAR 40-year reanalysis project. Bull Amer Meteorol Soc 77: 437-471

Lettenmaier DP, Gan TY (1990) Hydrologic sensitivities of the Sacramento-San Joaquin River basin, California, to global warming. Water Resour Res 26: 69-86

Leung LR, Qian Y, Bin X, Washington WM, Han J, Roads JO (2004) Mid-century ensemble regional climate change scenarios for the western United States. Clim Chang 62: 75-113

Loáiciga HA, Maidment DR, Valdes JB (2000) Climate-change impacts in a regional karst aquifer, Texas, USA. J Hydrol 227: 173-194

McKenzie D, Gedalof ZM, Peterson DL, and Mote PW (2004) Climatic change, wildfire, and conservation. Conserv Biol 18(4):890-902 
Meehl, GA, Stocker TF, Collins WD, Friedlingstein P, Gaye AT, Gregory JM, Kitoh A, Knutti R, Murphy JM, Noda A, Raper SCB, Watterson IG, Weaver AJ, and Zhao Z-C (2007) Global climate projections. in Climate change 2007: The Physical science basis. Contribution of working group I to the fourth assessment report of the Intergovernmental Panel on Climate Change [Solomon, S, et al., (eds)]. Cambridge University Press, Cambridge, United Kingdom and New York, NY, USA.

Mitchell TD, Carter TR, Jones PD, Hulme M, and New M (2004) A comprehensive set of climate scenarios for Europe and the globe: the observed record (1901-2000) and 16 scenarios (2001-2100). Tyndall Centre Working Paper No. 55, University of East Anglia, Norwich, UK.

Mote PW (2003) Trends in temperature and precipitation in the Pacific Northwest. Northwest Science 77: 271-282.

Mote PW, Mantua NJ (2002) Coastal upwelling in a warming future. Geophys Res Lett 29(23)

Mote PW, Salathé EP (2009) Future climate in the Pacific Northwest. Chapter 1 in The Washington Climate Change Impacts Assessment: Evaluating Washington's Future in a Changing Climate, Climate Impacts Group, University of Washington, Seattle, Washington.

Mote PW, Salathé EP, and Peacock C (2005) Scenarios of Future Climate for the Pacific Northwest. Climate Impacts Group, Joint Institute for the Study of the Atmosphere and Ocean, University of Washington. 13pp.

Mote PW, Peterson A, Reeder S, Shipman H, Whitely Binder L (2008) Sea level rise in the coastal waters of Washington state. Climate Impacts Group, Joint Institute for the Study of the Atmosphere and Ocean, University of Washington. 11pp

Nakićenović N, Swart R (eds.) (2000) Special report on emissions scenarios. A special report of working group III of the Intergovernmental Panel on Climate Change. Cambridge University Press, Cambridge, United Kingdom and New York, NY, USA, 599 pp

Palmer RN, Hahn MA (2002) The impacts of climate change on Portland's water supply: An investigation of potential hydrologic and management impacts on the Bull Run system. Report prepared for the Portland Water Bureau, University of Washington, Seattle. $139 \mathrm{pp}$

Randall DA, Wood RA, Bony S, Colman R, Fichefet T, Fyfe J, Kattsov V, Pitman A, Shukla J, Srinivasan J, Stouffer RJ, Sumi A, Taylor KE (2007) Climate models and their evaluation. In: Climate change 2007: The Physical science basis. Contribution of working group I to the fourth assessment report of the Intergovernmental Panel on Climate Change [Solomon, S, et al., (eds)]. Cambridge University Press, Cambridge, United Kingdom and New York, NY, USA

Raupach MR, Marland G, Ciais P, Le Quéré C, Canadell JG, Klepper G, Field CB (2007) Global and regional drivers of accelerating CO2 emissions. Proc Natl Acad Sci doi 10.1073/pnas.0700609104

Salathé EP (2005) Downscaling simulations of future global climate with application to hydrologic modeling. Int J Clim 25:419-436

Salathé EP, Mote PW, and Wiley MW (2007) Review of scenario selection and downscaling methods for the assessment of climate change impacts on hydrology in the United States pacific northwest. Int J Clim 27:1611-1621

Salathé EP, Steed R, Mass CF, and Zahn P (2008) A high-resolution climate model for the U.S. Pacific Northwest: Mesoscale feedbacks and local responses to climate change. J Clim 21:5708-5726

Salathé EP, Leung LR, Qian Y, Zhang Y (2009) Regional climate model projections for the State of Washington. Clim Chang, in preparation

Schellnhuber HJ, et al. (eds) (2006) Avoiding dangerous climate change. Cambridge University Press, New York, NY 
Stainforth, D.A., et al., 2005: Uncertainty in predictions of the climate response to rising levels of greenhouse gases. Nature, 433, doi: 10.1038/nature03301.

Taylor KE (2000) Summarizing multiple aspects of model performance in a single diagram. Report No. 55 of the Program for climate model diagnosis and intercomparison, Lawrence Livermore National Laboratory

Widmann M, Bretherton CS (2000) Validation of mesoscale precipitation in the NCEP reanalysis using a new gridcell dataset for the northwestern United States. J Clim 13: $1936-1950$

Widmann M, Bretherton CS, and Salathé EP (2003) Statistical precipitation downscaling over the Northwestern United States using numerically simulated precipitation as a predictor. J Clim 16:799-816

Wood AW, Maurer EP, Kumar A, and Lettenmaier DP (2002) Long-range experimental hydrologic forecasting for the eastern United States. J Geophys Res-Atmos 107:4429-4443

Zhang, X., Zwiers, F.W., Hegerl, G.C., Lambert, F.H., Gillett, N.P., Solomon, S., Stott, P.A, and Nozawa, T. 2007. Detection of human influence on twentieth-century precipitation trends. Nature: 06025, DOI:10.1038, 1-5.

Photo credit, page 23: iStockphoto.com 